\title{
Studying the effects of using nano-materials treated glass openings : A scale model case study
}

\section{Original Article}

Mahmoud Ahmed Zaki, Hosny Ahmed Dewer, Rasha Mohamed Dabaon

Department of Architectural Engineering, Faculty of Engineering, Tanta University, Tanta, Egyp

\section{Key words:}

Glass permeability coefficient, nano-materials, nanotechnology, ultraviolet radiation.

\section{Corresponding Author:}

Hosny Ahmed Dewer, Architecture Department, Faculty of Engineering, Tanta University, Tel: 01115300540.

Email: ha_dewer@yahoo.com.

\section{Abstract}

Nanotechnology is considered a modern science based on changing the physical specifications of materials. Is a nanometer-sized material called nanomaterials based on the science of atoms and molecules where it is integrated with physics, chemistry and biology sciences because it deals with a very small measurement unit and the use of these materials in architecture has become necessary, especially that nano-scale materials, especially glass treatment, reduce the permeability of glass to the solar radiation of the architecture space and are responsible for raising the temperature within the space in addition to the impact on the intensity of light which passing through the window architectural space. In this research, the use of some types of materials treated with nanotechnology in the treatment of glass used in the openings in the facades will be tested to determine the extent of their effect in reducing the permeability of solar radiation from the glass to reduce the temperature inside the space while at the same time testing the effect on the intensity of natural light within the architectural space.

\section{I- INTRODUCTION}

Nanotechnology is not a new science and it is not a new technology either. It is rather an extension of the sciences and technologies that have already been in development for many years and it is the logical progression of the work that has been done to examine the nature of our world at ever smaller and smaller scale ${ }^{[1]}$.

The use of nanomaterials in architecture will present new opportunities to solve problems and lead the building structure and architecture to an optimum level by significantly improving the nature of building structure and efficiency and the way buildings relate to the environment ${ }^{[8]}$.

Nanomaterials can expand design possibilities for both interior and exterior spaces. Their use can open up new possibilities for sustainable design strategies and provide a new array of functions that would help interaction between the occupants and the building ${ }^{[9]}$.

There is currently an extraordinary amount of interest in (nanomaterials) and nanotechnologies, terms now familiar not only to scientists, engineers, architects, and product designers but also to the general public. (Nanomaterials) and nanotechnologies have been developed as a consequence of truly significant recent advances in the material science community ${ }^{[2]}$.

\section{DEFINITION}

Nanotechnology, shortened to "nanotech", is the study of the control of matter on anatomic and molecular scale.
Generally, nanotechnology deals with structures of the size 100 nanometers or smaller in at least one dimension ${ }^{[3]}$. The word nano is a scientific prefix that stands for 10-9 or one-billionth; the word itself comes from the Greek word nanos, meaning dwarf $\mathrm{f}^{[4]}$.

Nanotechnology is the study of phenomena and finetuning of materials at atomic, molecular and macromolecular scales, where properties differ significantly from those at a larger scale. Products based on nanotechnology are already in use and analysts expect markets to grow by hundreds of billions of euros during this decade ${ }^{[6]}$.

\section{RESEARCH METHODOLOGY}

Research is being carried out on the application of nanotechnology to glass. Titanium dioxide (TiO2) nanoparticles are used to coat glazing since it has sterilizing and anti-fouling properties. The particles catalyze powerful reactions that break down organic pollutants, volatile organic compounds and bacterial membranes. $\mathrm{TiO} 2$ is hydrophilic (attraction to water), which can attract rain drops that then wash off the dirt particles. Thus the introduction of nanotechnology in the glass industry incorporates the self-cleaning property of glass ${ }^{[5]}$.

Also, we can use a protection film on glass which is another application of nanotechnology. This is achieved by using a clear intumescent layer on glass panels formed of silica nanoparticles $(\mathrm{SiO} 2)$, which turns into a rigid and opaque heat shield when heated. Most of the glass used in construction is on the exterior surface of buildings. So, the 
light and heat entering the building through glass (have) to be prevented. Nanotechnology can provide a better solution to block heat coming through windows and allow light. Glass facades for buildings form a large scope for nano technological innovations in the construction industry ${ }^{[7]}$.

This study is based on a comparison between ordinary glass and glass treated with nanomaterials on a laboratory model with a 1:2 ratio in the following variables:

A- The temperature degree.

B- The intensity of illumination.

This research is based on studying the results of the use of nanotechnology on glass in the architectural facades of the four directions. The practical experience of a room made of wood with a window opening was made. Three variables were selected for standard glass panels with fixed thickness $(6 \mathrm{~mm})$ and dimensions of $60 \mathrm{~cm} \times 100 \mathrm{~cm}$ to deal with them as follows:

1- The first panel of ordinary glass without any treatments.

2- The second panel is treated with a $3 \mathrm{M}$ Prestige 70 thermal insulation film on its inner surface and a single layer of self-cleaning nanoparticles from NANO G7 sprayed on the outside.

3- The third panel is treated with (a 3M Prestige 70 thermal insulation film on its inner surface) only.

\section{VI- EFFECT OF GLASS ON THE PROCESS OF THERMAL TRANSITION FROM THE OUTSIDE TO THE INSIDE}

Glass is the main material used in windows, and usually the type of glass is chosen based on its ability to transmit light, ; its impact on the comfort of the population in terms of light penetration, heat transfer and self-cleaning ; its settings ; its strength and safety; as well as the cost of its life cycle.

Glass is divided into several types: pure glass, transparent, semi-transparent, antiseptic, reflector, single, double and glass treated by nanotechnology ${ }^{[11]}$.

Glass is the biggest weakness (with respect to) heat transfer in buildings, which depends on several factors of glass:

1- Thickness of glass.

2- The area of glass.

3- The type of glass

The amount of solar radiation transmitted through the glass panel varies depending on:

A- The radiation permeability value of direct solar radiation depends on the angle of radiation fall on the glass plate. The more radiation on the glass, the greater the value of the glass permeability factor. In general, the value of the permeability coefficient is high when the angle of radiation slope between 50-90 degrees, but it decreases rapidly when the angle is less than $40^{[13]}$.

B-Glass panels are made of different colors and qualities, which affect the amount of thermal solar radiation in force. The (following) figure shows a comparison between the values of the permeability coefficient depending on the quality of the pure glass and the heat ${ }^{[11]}$.
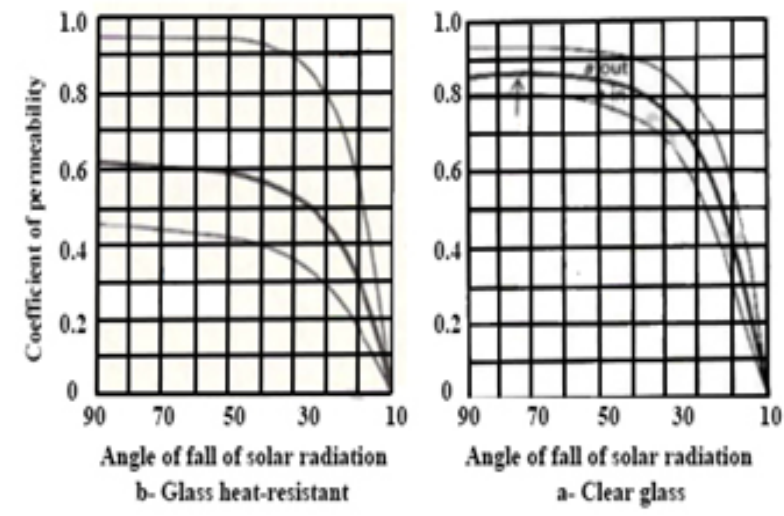

Fig. 1: Shows (a) comparison between ordinary glass and absorbent glass in terms of (angle of solar radiation fall and permeability coefficient.

\section{V- TOTAL SOLAR PERMEABILITY AND PHOTOVOLTAIC PERMEABILITY FOR DIFFERENT TYPES OF GLASS}

There are several types of glass that can reduce the passing amount of solar radiation in general and there are more advanced glass types that can select between increasing the coefficient of permeability and reducing the coefficient of heat transfer through modern techniques of glass $^{[12]}$.

Table 1: Total solar permeability and photovoltaic permeability for different types of glass

\begin{tabular}{lccc}
\hline Glass type & $\begin{array}{c}\text { Optical } \\
\text { transmittance }\end{array}$ & $\begin{array}{c}\text { Total solar } \\
\text { permeability }\end{array}$ & $\begin{array}{c}\text { Thickness } \\
\text { of glass }\end{array}$ \\
\hline Clear glass & 0.90 & 0.86 & $3 \mathrm{~mm}$ \\
Bronze & 0.88 & 0.81 & $6 \mathrm{~mm}$ \\
& 0.68 & 0.73 & $3 \mathrm{~mm}$ \\
Gray & 0.54 & 0.62 & $6 \mathrm{~mm}$ \\
& 0.62 & 0.70 & $3 \mathrm{~mm}$ \\
Green & 0.46 & 0.59 & $6 \mathrm{~mm}$ \\
Reflective & 0.82 & 0.70 & $3 \mathrm{~mm}$ \\
$(30 \%)$ & 0.76 & 0.60 & $6 \mathrm{~mm}$ \\
\hline
\end{tabular}

\section{VI- THE APPLIED STUDY}

In this study, we conducted experiments in two phases: Phase 1: The case of a chamber that is not isolated. The results were close and there were no significant differences in temperature between the inside and outside.

Phase 2: After isolating the chamber from the outside with white polystyrene with thickness of $5 \mathrm{~cm}$.

In this research, the results of the following variables were monitored:

1- Temperatures outside and inside the room, which were measured by two devices to ensure accuracy. 
2- Intensity of illumination inside.

The methodology of this study is based on the following:

1- The model used in the practical experience.

2- Instruments used in measurement.

3- A comparison between the different types of glass (measurement time throughout the day).

\section{VII- THE MODEL (STANDARD ROOM)}

The room was applied with a dimension of $160 \mathrm{~cm} \mathrm{x}$ $240 \mathrm{~cm}$ and $160 \mathrm{~cm}$ height, where we installed the room on four wheels to facilitate steering in the four directions. The room was isolated by a layer of white polystyrene with thickness of $5 \mathrm{~cm}$ with a door opening (to) the opposite side of (a) glass window with dimensions of $100 \mathrm{~cm} \times 60 \mathrm{~cm}^{[14]}$.

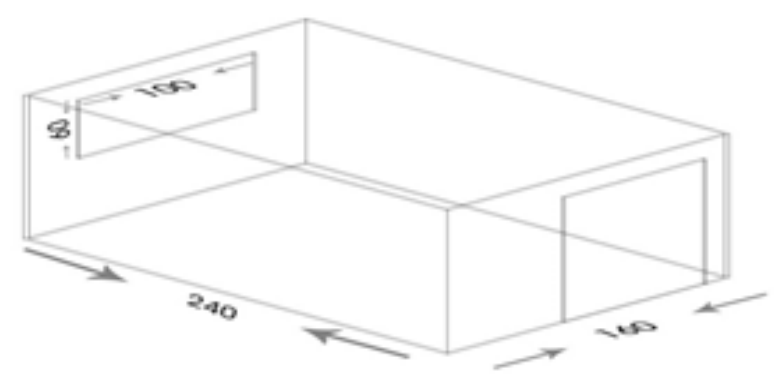

Fig. 2: The model room

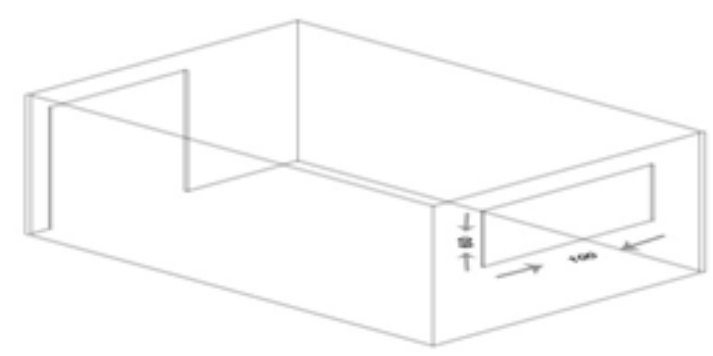

Fig. 3: The dimension of the window wall of the model room.

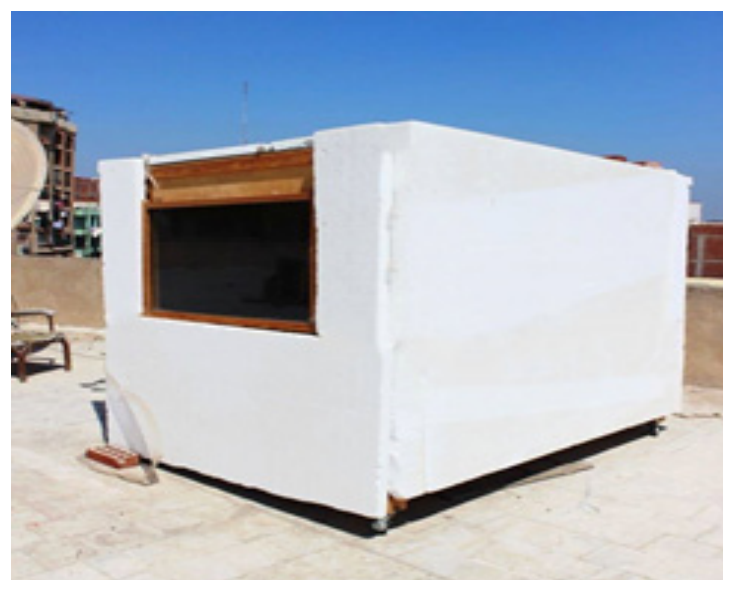

Fig. 4: The model room from outside.

\section{VIII- THE MEASURING DEVICES}

According to the methodology of the study what is required is to determine the temperature differences between the inside and outside of each type of glass used in the experiment, and therefore there is no need to calibrate the device. The following devices were used:

1- Two devices to measure the temperature and humidity outside and inside the room using the Celsius (unit of measurement) (TFA Dostmann/Wertheim).

2- A lux meter device, the Amprobe LM-120, to measure the intensity of light (lux).

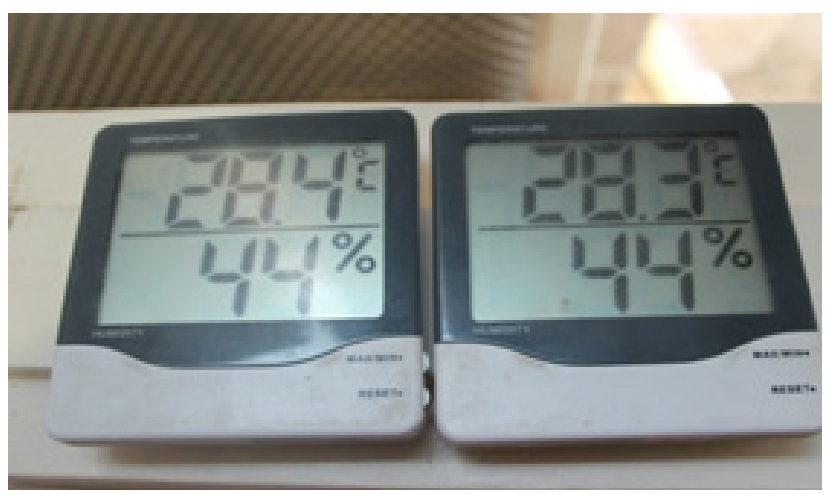

Fig. 5: The temperature and humidity devices.

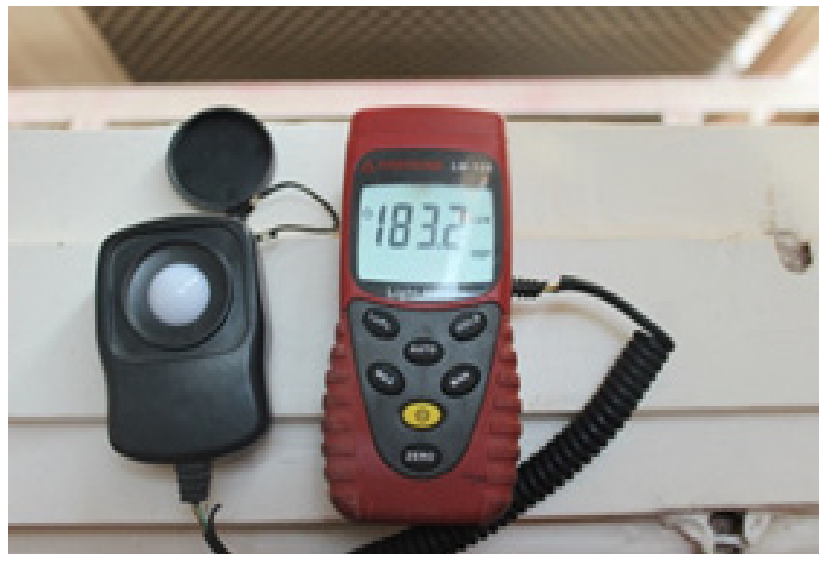

Fig. 6: The lux meter device.

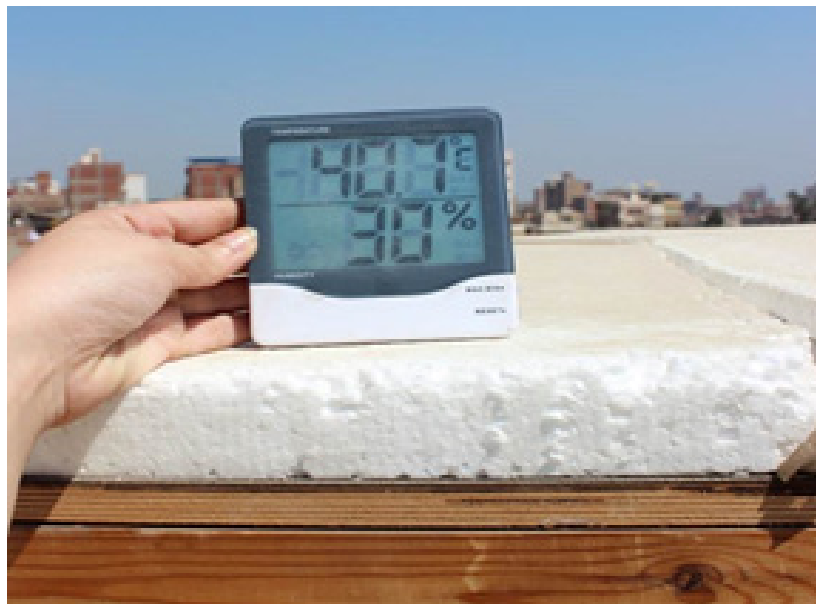

Fig. 7: The measurement outside the room. 


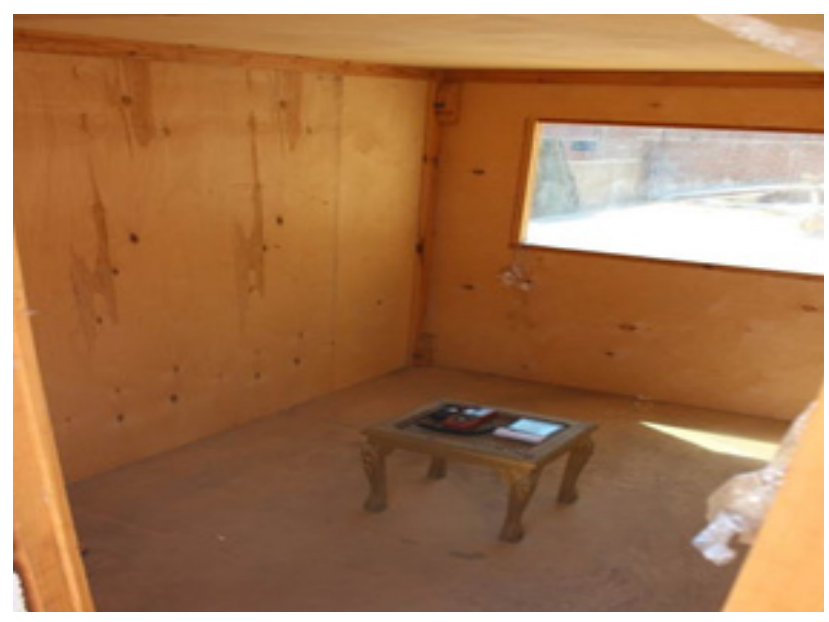

Fig. 8: The measurement inside the room.

\section{VIIII- SPECIFICATIONS FOR GLASS INSULATION MATERIALS}

In these practical experiments, we used two types of insulation:

A- A film installed on glass called (Prestige 70) according to the following specifications:

Table 2: The Specifications (Prestige 70)

\begin{tabular}{lcc}
\hline \multirow{2}{*}{ FILM PR 70 } & \multicolumn{2}{c}{ Single panel } \\
& Clear 6m & PR70 6m \\
\hline Solar Heat Gain Coefficient & 0.82 & 0.50 \\
Visible Light Transmitted & $89 \%$ & $69 \%$ \\
Visible Light Reflected Interior & $9 \%$ & $9 \%$ \\
Visible Light Reflected Exterior & $8 \%$ & $9 \%$ \\
U Value & 1.03 & 0.099 \\
UV Block & $38 \%$ & $99.9 \%$ \\
Total Solar Energy Rejected & $19 \%$ & $50 \%$ \\
Glare Reduction & NA & $22 \%$ \\
Heat Loss Reduction & NA & $3 \%$ \\
Solar Loss Reduction & NA & $38 \%$ \\
\hline
\end{tabular}

B- A NANO G7 spray for self-cleaning on the outside.

It is water and oil repellency on glass and ceramic surface. Glass and ceramic surfaces attract less dirt and are cleaned easily when G7 is applied. Sprayed ceramic parts are prevented from fouling.

Simply spray and wipe down with a cotton cloth. The surface can be used after 16 hours of application.

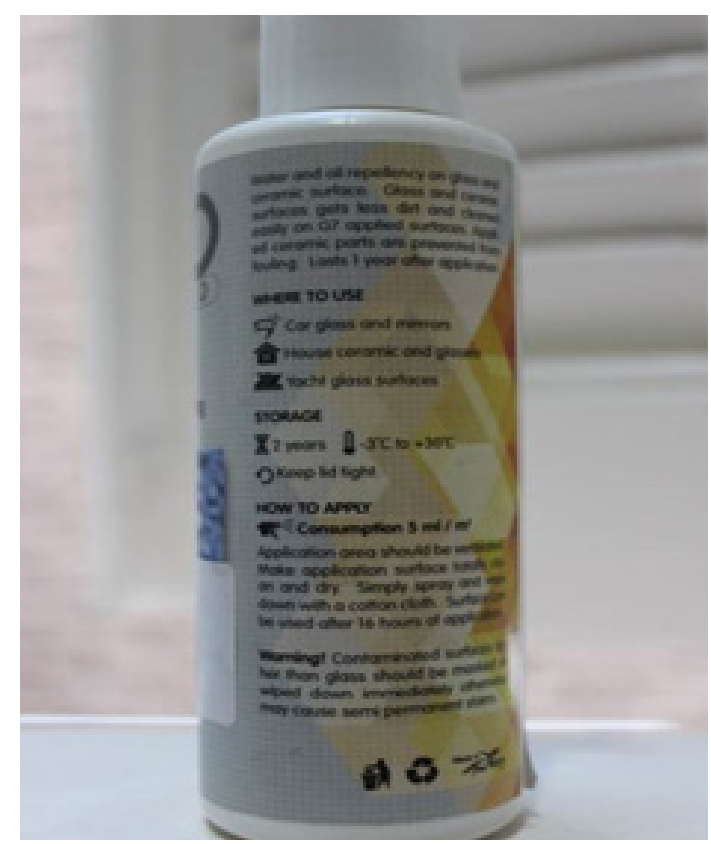

Fig. 9: The measurement inside the room

\section{X- METHODOLOGY OF MEASUREMENT EXPERIMENT FOR TEMPERATURE DIFFERENCES IN-OUTSIDE OF THE ROOM}

The measurements for each type of glass were monitored in the four directions (East, North, West and South) at specified times (9 am, $11 \mathrm{am}, 1 \mathrm{pm}$ and $3 \mathrm{pm}$ ) for 3 consecutive days, but after the insulation on the room with a layer of polystyrene $5 \mathrm{~cm}$ and in 3 consecutive days for each type of test glass, To avoid the negative effect of heat transfer from outside into the room. Since the experiment of the chamber without isolation, measured values for external and internal temperatures were almost equal. The following graphs show the results of the laboratory measurements regarding the effect of the time and the external temperature on the interior.

\section{A - The East side of the three types of glass}

Figure 10 shows the relationship between time and the ratio of external temperature to the interior at specified times ( $9 \mathrm{am}, 11 \mathrm{am}, 1 \mathrm{pm}$ and $3 \mathrm{pm}$ ) for the three different types of glass when the room is isolated with $5 \mathrm{~cm}$ white polystyrene.

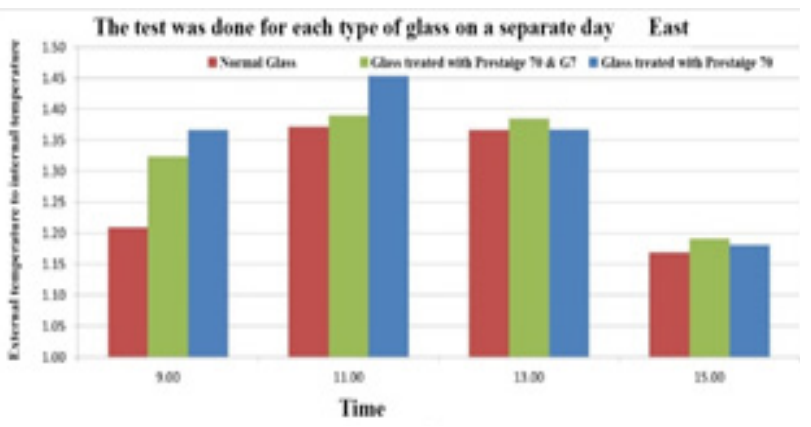

Fig. 10: The ratio of external temperature to the interior at the specified times for the three different types of glass in East direction. 


\section{B - The North side of the three types of glass}

Figure 11 shows the relationship between time and the ratio of external temperature to the interior at specified times ( $9 \mathrm{am}, 11 \mathrm{am}, 1 \mathrm{pm}$ and $3 \mathrm{pm})$ for the three different types of glass when the room is isolated with $5 \mathrm{~cm}$ white polystyrene.

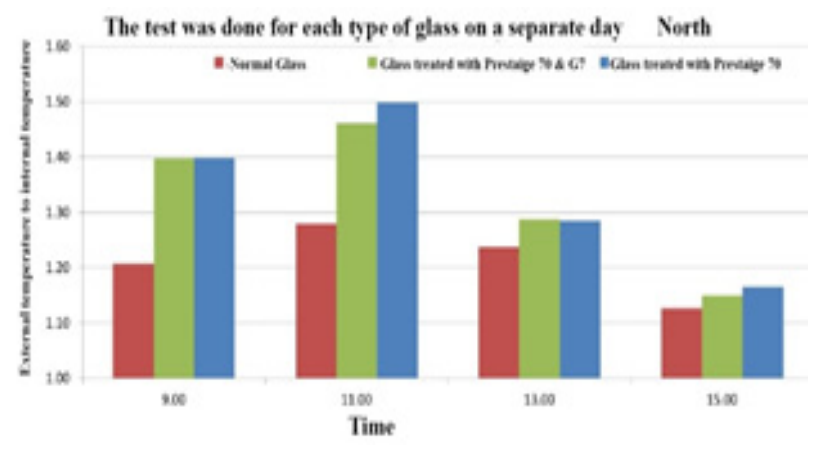

Fig. 11: The ratio of external temperature to the interior at the specified times for the three different types of glass in North direction.

\section{C - The South side of the three types of glass}

Figure 12 shows the relationship between time and the ratio of external temperature to the interior at specified times ( $9 \mathrm{am}, 11 \mathrm{am}, 1 \mathrm{pm}$ and $3 \mathrm{pm}$ ) for the three different types of glass when the room is isolated with $5 \mathrm{~cm}$ white polystyrene.

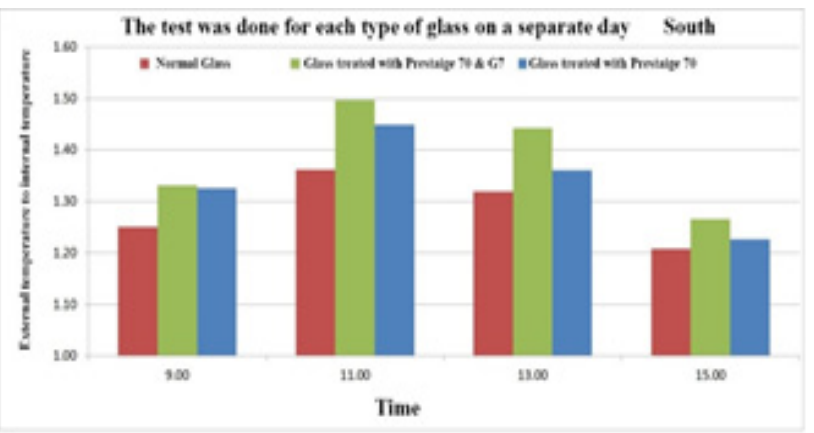

Fig. 12: The ratio of external temperature to the interior at the following times the three different types of glass in South direction.

\section{D - The West side of the three types of glass}

Figure 13 shows the relationship between time and the ratio of external temperature to the interior at the specified times ( $9 \mathrm{am}, 11 \mathrm{am}, 1 \mathrm{pm}$ and $3 \mathrm{pm}$ ) for the three different types of glass when the room is isolated with $5 \mathrm{~cm}$ white polystyrene

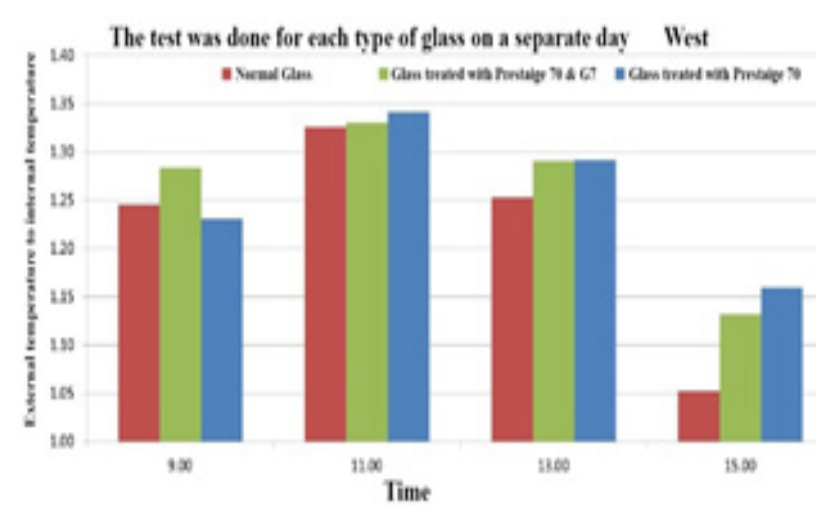

Fig. 13: The ratio of external temperature to the interior at the specified times for the three different types of glass in West direction.

\section{X- METHODOLOGY OF MEASUREMENT EXPERIMENT FOR THE INTENSITY OF LIGHTING INSIDE THE ROOM}

The intensity of illumination in the room was measured in 3 consecutive days for the three types of glass. The following graphs show a comparison between the intensity of light for the four directions.

\section{A - The East side of the three types of glass}

Figure 14 shows the relationship between time and intensity of light at specified times ( $9 \mathrm{am}, 11 \mathrm{am}, 1 \mathrm{pm}$ and $3 \mathrm{pm})$ for the three different types of glass when the room is isolated with $5 \mathrm{~cm}$ white polystyrene.

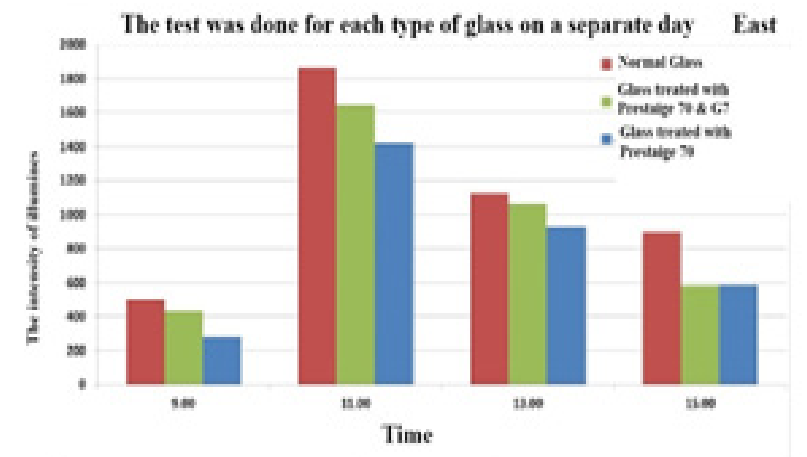

Fig. 14: The intensity of light at the specified times for the three different types of glass in East direction.

\section{B - The North side of the three types of glass}

Figure 15 shows the relationship between time and intensity of light at specified times ( 9 am, $11 \mathrm{am}, 1 \mathrm{pm}$ and $3 \mathrm{pm}$ ) for the three different types of glass when the room is isolated with $5 \mathrm{~cm}$ white polystyrene. 


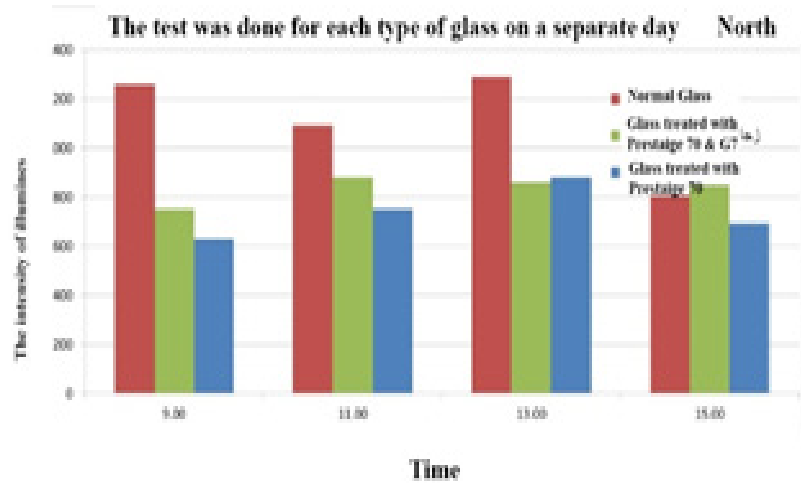

Fig. 15: The intensity of light at the specified times for the three different types of glass in North direction

\section{C - The South side of the three types of glass}

Figure 16 shows the relationship between time and intensity of light at specified times ( $9 \mathrm{am}, 11 \mathrm{am}, 1 \mathrm{pm}$ and $3 \mathrm{pm}$ ) for the three different types of glass when the room is isolated with $5 \mathrm{~cm}$ white polystyrene.

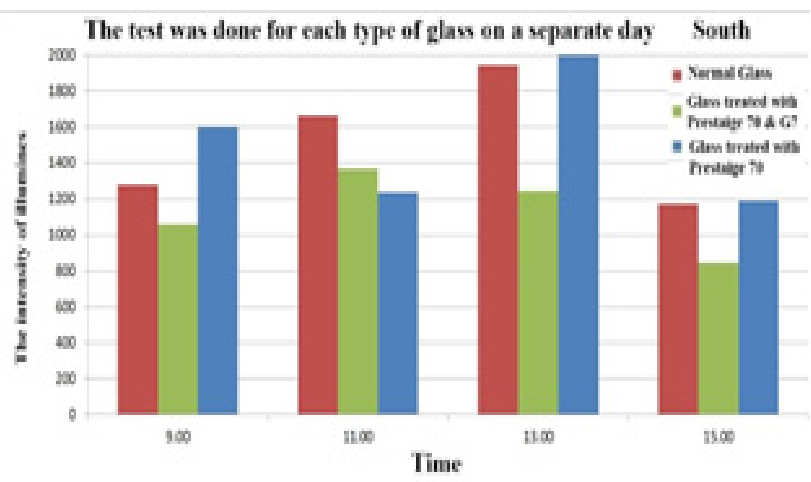

Fig. 16: The intensity of light at the specified times for the three different types of glass in South direction.

\section{D - The West side of the three types of glass}

Figure 17 shows the relationship between time and intensity of light at specified times ( 9 am, $11 \mathrm{am}, 1 \mathrm{pm}$ and $3 \mathrm{pm}$ ) for the three different types of glass when the room is isolated with $5 \mathrm{~cm}$ white polystyrene.

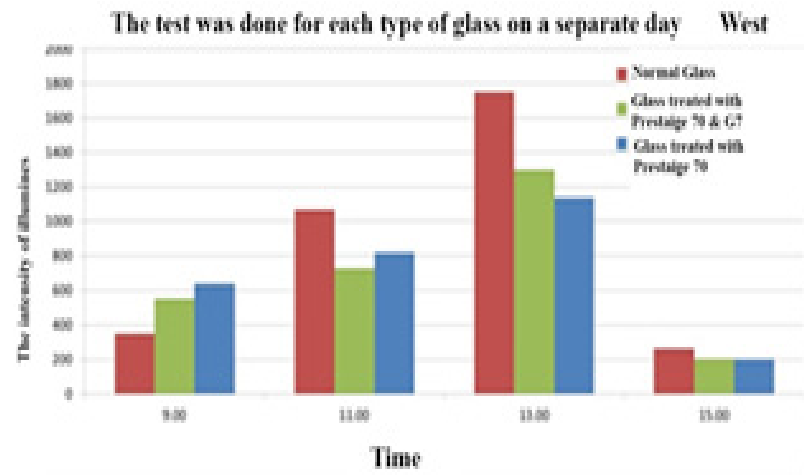

Fig. 17: The intensity of light at the specified times for the three different types of glass in West direction.

\section{XI- ANALYSIS OF RESULTS}

The practical measurements of the experiment were measured in terms of the ratio of reduction of heat bikes from outside the room to the inside and the intensity of the light inside the room for the three types of glass being tested in the four directions and at specified times between 9 am and $3 \mathrm{pm}$.

Table 3: The percentage of temperature reduction from outside the room to the inside.

\begin{tabular}{|c|c|c|c|c|c|}
\hline \multicolumn{6}{|c|}{$\begin{array}{l}\text { Percentage of temperature reductio } \\
\text { the inside } \\
\Delta=(1 / 4) \sum_{q_{\omega}}^{3_{2}} \frac{t_{0}-t_{i}}{t_{i}} \%\end{array}$} \\
\hline South & West & North & East & Glass type & Time \\
\hline $28.5 \%$ & $22 \%$ & $21 \%$ & $28 \%$ & normal & \multirow{3}{*}{$\begin{array}{l}9 \mathrm{am} \\
\vdots \\
3 \mathrm{pm}\end{array}$} \\
\hline $38.5 \%$ & $25.8 \%$ & $32 \%$ & $32 \%$ & NANO G7 & \\
\hline $34.3 \%$ & $25.5 \%$ & $33.5 \%$ & $34.3 \%$ & $\begin{array}{l}\text { (Prestige) } \\
70\end{array}$ & \\
\hline
\end{tabular}

To $=$ external temperature

$\mathrm{Ti}=$ internal temperature

$\square=$ average 4 temperature readings hourly from 9 am to $3 \mathrm{pm}$.

Table 4: The intensity of light in the middle of room.

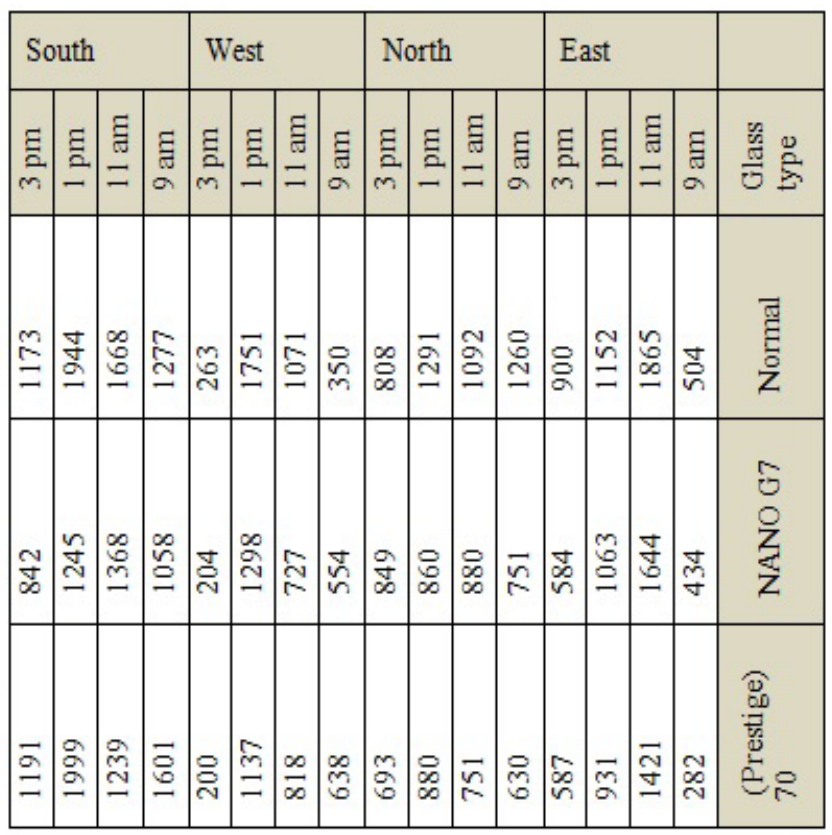




\section{XIII- STUDY RESULTS AND CONCLUSIONS}

1- The role of glass in reducing temperature is vital. 2. Nanotechnology applications on materials have a significant positive impact on the architectural product. 3- Use of glass treated with nanotechnology

- PR70 Exterior Window Film.

- Glass Film Exterior PR70 and Nano G7

It was found that it works to reduce energy and reduce the thermal loads on the building and through the practical experience and comparing the results of temperatures from outside the room to the inside, which expressed a difference in temperature in the space. It was found that it is better to use PR70 glass and Glass Film Exterior PR70 and Nano, as they reduce heat and provide energy in the four directions (East, North, West and South), based on the following results:

Table 5: The percentage of heat reduction from outside the room to the inside and the intensity of the light.

\begin{tabular}{|c|c|c|c|c|c|c|c|c|}
\hline \multicolumn{2}{|r|}{ East } & \multicolumn{2}{|c|}{ North } & \multicolumn{2}{|c|}{ South } & \multicolumn{2}{|c|}{ West } & \multirow[b]{2}{*}{ 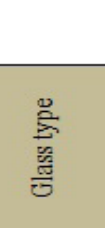 } \\
\hline 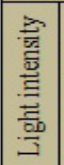 & 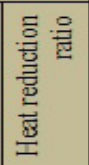 & 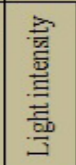 & 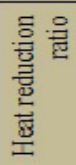 & $\begin{array}{l}\text { 哥 } \\
\text { 总 } \\
\text { 总 } \\
\text { 总 }\end{array}$ & 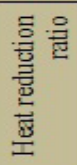 & 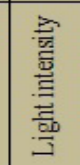 & 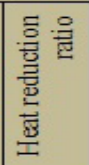 & \\
\hline 官 $d$ & $\stackrel{\circ}{\stackrel{\sim}{\sim}}$ & 100 & $\stackrel{\circ}{\sim}$ & $10^{\circ}$ & $\stackrel{\circ}{\stackrel{0}{\sim}}$ & E。 & $\stackrel{\circ}{\stackrel{े}{*}}$ & 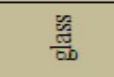 \\
\hline$\stackrel{\circ}{\circ}$ & $\stackrel{\text { ळे }}{\circ}$ & $\stackrel{\circ}{\approx}$ & $\stackrel{\circ}{\stackrel{\rho}{m}}$ & $\underset{⿱}{\stackrel{D}{*}}$ & ळे & $\frac{\circ}{\infty}$ & $\begin{array}{l}\stackrel{\circ}{ } \\
\infty \\
\approx\end{array}$ & 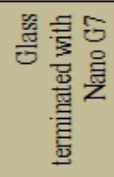 \\
\hline مْ & $\begin{array}{l}\stackrel{\circ}{m} \\
\text { 峁 }\end{array}$ & $\stackrel{8}{8}$ & $\stackrel{\circ}{\ddot{m}}$ & $\stackrel{\circ}{\infty}$ & $\begin{array}{l}\stackrel{\circ}{m} \\
\text { 峁 }\end{array}$ & $\stackrel{\stackrel{\circ}{\circ}}{\frac{\infty}{\infty}}$ & $\begin{array}{l}\stackrel{0}{\ddot{2}} \\
\approx\end{array}$ & 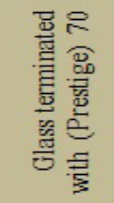 \\
\hline
\end{tabular}

By comparing the temperature results from outside the room to the inside, it became clear that it is better to use the PR70 glass and the Glass Exterior PR70 and Nano G7, which reduce heat and provide energy in the four directions (East, North, West and South).

So, the best treatments of glass using nanotechnology in terms of temperature reduction and intensity of light are: 1- In (North and East facades) PR70 treated glass and self-cleaning (Nano G7) is the best treatment for intensity of light, but a glass treated using PR70 only in the best treatment for temperature reduction.

2- In (South and West facades) PR70 treated glass and selfcleaning (Nano G7) is the best treatment for temperature reduction, but a glass treated using PR70 only is the best treatment for intensity of light.

\section{XIIII- REFERENCES}

[1] Nanoforum.org, European Nanotechnology Gateway, Nanoforum report: Nanotechnology and Construction, November 2006.

[2] Michael F. Ashby, Paulo J. Ferreira, Daniel L. Schodek, NanoMaterials, NanoTechnologies and Design, An Introduction for Engineers and Architects, Elsevier Ltd,2009.

[3] Nanotechnology http://en.wikipedia.org/wiki/Nanotechnology, retrieved, october, 2009

[4] Patel Abhiyan S. 1, Rathod Hiren A.2 ,Neeraj SharmaD. An Overview on Application of Nanotechnology in Construction Industry, International Journal of Innovative Research in Science, Engineering and Technology, 2013.

[5] ZhiGe, ZhiliGao,"Advancing and Integrating Construction Education, Research \& Practice", Applications of Nanotechnology and Nanomaterials in ConstructionFirst International Conference on Construction In Developing Countries (ICCIDC-I), August 4-5, 2008, Karachi, Pakistan

[6] (GREEN NANOARCHITECTURE- By Architect fahd abd elaziz ahmed omar hemeida- B.Sc. of architecture- university of AlexandriaJanuary 2010).

[7] NanoArchitecture Nanotechnology and Architecture University of Alexandria, Faculty of Engineering, Department of Architecture by Architect Maged Fouad El-Samny B.Sc. of Architecture University of Alexandria 2008

[8] Nano Materials in architecture, Interior architecture and Design. Leydecker, Sylvia (2008).

[9] Nano materials for architecture enrico ercolani _ department of industrial engineering _via del politecnico 1.00133, Roma, Italy. 